\title{
The behavior of protein-calorie-malnourished rats on the elevated plus-maze test: An ethopharmacological analysis
}

\author{
GABRIELA M. S. MOREIRA, MARIÉLENA DE ARAÚJO, \\ LUIZ M. DE OLIVEIRA, and SEBASTIÃO S. ALMEIDA \\ University of São Paulo, Ribeirão Preto, São Paulo, Brazil
}

\begin{abstract}
In order to study the effects of the protein-calorie malnutrition on the behavior of rats submitted to the elevated plus-maze, an ethopharmacological analysis was used. Litters (dam plus 6 male pups) were fed ad lib (control) or were fed $50 \%$ of the amount of diet consumed by the control group (malnourished) from birth to 49 days of age. From Day 50 on, all rats were fed ad lib. At 70 days of age, the animals were pharmacologically treated (vehicle or diazepam, 1.5 and $3.0 \mathrm{mg} / \mathrm{kg}$ ) and were placed, $30 \mathrm{~min}$ later, in the center of the elevated plus-maze for a 5 -min session. During this session, 11 behaviors believed to indicate anxiety or exploration were measured. The results showed that protein-calorie malnutrition results in increased exploration of the open arms of the maze, higher latency of first arm entry, and lower closed-arm returns, indicating lower anxiety or higher impulsiveness. In addition, the protein-calorie-malnourished rats were hyporeactive to the anxiolytic effects of diazepam, indicating possible alterations in the GABA-benzodiazepine system as result of the malnutrition procedure.
\end{abstract}

Protein malnutrition early in life results in morphological, neurochemical, and behavioral changes that persist even after a long period of nutritional rehabilitation (Dobbing, 1987; Levitsky \& Strupp, 1995; Morgane et al., 1993; Morgane, Austin-LaFrance, Bronzino, Tonkiss, \& Galler, 1992; Morgane et al., 1978; Strupp \& Levitsky, 1995).

Recently, it has been shown that protein malnutrition during the gestational and/or lactational periods changes the behavior of rats in animal models of anxiety. Lower anxiety has been shown for malnourished animals submitted to light-dark transition tests (Brioni \& Orsingher, 1988; Santucci, Daud, Almeida, \& de Oliveira, 1994), elevated plus-maze tests (Almeida, de Oliveira, \& Graeff, 1991; Almeida et al., 1994; Almeida, Garcia, \& de Oliveira, 1993; Almeida, Tonkiss, \& Galler, 1996c), and elevated T-maze tests (Almeida, Tonkiss, \& Galler, 1996b). This altered behavior of malnourished animals in some models of anxiety has been interpreted as higher impulsiveness of these animals in a naturalistic aversive situation (Almeida et al., 1994; Almeida et al., 1996c; Santucci

This work was supported by Research Grants 530060/93-0 and 523325/ 95-9 from Conselho Nacional de Desenvolvimento Cientifico e Tecnológico and Fundação de Amparo à Pesquisa do Estado de São Paulo (Proc. 95/9501-2). S.S.A. and L.M.d.O. were recipients of Research Fellowships from the Conselho Nacional de Desenvolvimento Cientifico e Tecnológico. G.M.S.M. and M.d.A. were recipients of a scholarship from Fundação de Amparo à Pesquisa do Estado de Sào Paulo. The authors thank Dalmo C. P. Nicola for technical assistance. Correspondence should be addressed to S. S. Almeida, Laboratory of Nutrition and Behavior, FFCLRP-USP, Avenida dos Bandeirantes, 3900, Ribeirão Preto, SP, Brazil, 14040-901 (e-mail: sebasalm@usp.br). et al., 1994). In addition, it has been demonstrated, in a variety of animal models of anxiety, that protein malnutrition changes the reactivity of rats to benzodiazepine (Almeida, de Oliveira, Bichuette, \& Graeff, 1988; Almeida, de Oliveira, \& Graeff, 1990, Almeida et al., 1994; Almeida, Soares, Bichuette, Graeff, \& de Oliveira, 1992; Brioni, Córdoba, \& Orsingher, 1989; Brioni \& Orsingher, 1988) and nonbenzodiazepine anxiolytic drugs (Almeida et al., 1990, 1991). Changes in the reactivity of malnourished animals to these drugs have been interpreted as the result of neuroanatomical and/or neurochemical changes produced by early protein malnutrition on central GABAbenzodiazepine and serotonergic neurotransmitter systems (Almeida, Tonkiss, \& Galler, 1996a, for a review).

However, the changes in reactivity to anxiolytic drugs in animal models of anxiety have been restricted to animals experiencing both pre- and postnatal protein malnutrition. Considering that one of the most prevalent situations of malnutrition in human population is protein-calorie malnutrition (de Onís, Monteiro, Akré, \& Clugston, 1993) and that changes in reactivity to anxiolytic drugs can be of relevance for therapeutic purposes, it would be interesting to study this kind of malnutrition. Therefore, the main aim of this study was to investigate the effects of protein-calorie malnutrition on the reactivity of rats to a benzodiazepine anxiolytic drug (diazepam) using the elevated plus-maze test. In addition to classical measures taken from this anxiety model (Pellow, Chopin, File, \& Briley, 1985), we incorporated elements of an ethological analysis as described in previous studies (Almeida et al., 1994; Almeida et al., 1993; Almeida et al., 1996b; Cole \& Rodgers, 1994; Cruz, Frei, \& Graeff, 1994; Rodgers \& Cole, 1993a, 1993b). 


\section{METHOD}

\begin{abstract}
Subjects
Eighty-four male Wistar rats from the animal colony of the campus of Ribeirão Preto of the University of São Paulo were used. During the lactation period ( 21 days), each litter was culled to 6 male pups on the day of birth. From that day on, half of the animals were suckled by mothers maintained on an ad-lib commercial diet (Purina), and the other half were suckled by mothers receiving $50 \%$ of the amount of the diet consumed by the ad-lib control group After weaning, the animals were housed individually; the malnourished rats continued to receive $50 \%$ of the amount of diet consumed by the animals of the control group until the 49th day of age. From Day 50 on, all rats were housed in pairs and fed ad lib, since previous pilot studies in our lab showed that social contact increases exploration in the elevated plus-maze. At 70 days of age, the animals were pharmacologically treated and tested in the elevated plus maze. The animals were maintained under a 12:12-h light:dark cycle (lights on at 7 a.m.). The room temperature was kept at $23^{\circ}-$ $25^{\circ} \mathrm{C}$. The experiment was conducted in the dark portion of the cycle.
\end{abstract}

\begin{abstract}
Apparatus
Red ceiling light $(40 \mathrm{~W})$ provided illumination in the experimental room where the elevated plus-maze was located. The wooden elevated plus-maze consisted of two open arms $(50 \times$ $10 \mathrm{~cm}$ ) opposite to each other, crossed by two enclosed arms $(50 \times$ $10 \times 40 \mathrm{~cm}$ ) with an open roof (Pellow et al., 1985). The maze was elevated $50 \mathrm{~cm}$ from the ground floor.
\end{abstract}

\section{Drugs}

Diazepam (Roche) was suspended in distilled water containing $2 \%$ Tween 80 and was injected i.p. in concentrations of $1 \mathrm{mg} / \mathrm{kg}$.

\section{Procedure}

At 70 days of age. independent groups $(n=10-12)$ of prenatally malnourished and well-nourished rats were (1) not treated, (2) injected with vehicle, or (3) given diazepam $(1.5$ and $3.0 \mathrm{mg} / \mathrm{kg}$ ). Thirty minutes following the injection, the animals were placed individually in the center of the maze facing an enclosed arm and allowed to explore for $5 \mathrm{~min}$. The test session was recorded by a vertical mounted videocamera (Sony) linked to a monitor and VCR in an adjacent room. The videotapes were later analyzed by an experimenter, and the following behavioral categories, as previously described (Almeida et al., 1994; Almeida et al., 1993; Almeida et al., 1996b; Cole \& Rodgers, 1994; Cruz et al., 1994; Rodgers \& Cole, 1993a, 1993b), were recorded: (1) the percentage of open-arm entries (arm entry defined as the rat having all four paws in an arm), (2) the percentage of time spent in the open arms, (3) closed-arm entries, (4) time in the central platform, (5) latency to first arm entry (latency to enter an arm timed from the start of the test), (6) stretch-attend posture (forward elongation of head and shoulders followed by retraction to the original position), (7) attempts to enter open arms (entering an open arm with only the forepaws and returning to the central platform or closed arm), (8) closed-arm returns (exiting a closed arm with the forepaws only and then returning into the same arm), (9) rearing (rising on the hind paws), (10) grooming (licking paws, moving paws over the head from ears to snout, licking body, and scratching flanks with a hind paw), and (11) head-dipping (scanning over the sides of the maze toward the floor). The behavioral categories of closed-arm returns, head-dips, and stretch-attend posture have been previously described as riskassessment behaviors (Almeida et al., 1994; Rodgers \& Cole, 1993a, 1993b). The rearing category was included as a classical measure of exploration in a novel environment (Almeida et al., 1994; Almeida et al., 1996c). The other behavioral categories have been described as indicators of anxiety and have been validated behaviorally and pharmacologically for rats (Cruz et al., 1994; Pellow et al., 1985) and mice (Cole \& Rodgers, 1994; Lister, 1987; Rodgers \& Cole, 1993a, 1993b).

\section{Statistical Analyses}

The body weights of the nutritional groups were compared by Student's $t$ test at 70 days of age. Behavioral measures in the elevated plus-maze vere analyzed by a two-way (diet and pharmacological treatment) analysis of variance (ANOVA). Post hoc comparisons were made using Dunnett's test. Because the behavior displayed by the nontreated animals did not differ from that of the vehicle-treated ones, the results of these two groups were combined.

\section{RESULTS}

\section{Body Weight}

Body weights at the age of testing (Day 70) were $343.3 \pm$ $4.2 \mathrm{~g}$ and $260.7 \pm 2.9 \mathrm{~g}$ for control and malnourished rats, respectively. The difference was statistically significant $[t(122)=16.36, p<.001]$.

\section{Behavioral Measures}

An ANOVA indicated a higher percentage of openarm entries for malnourished animals, as shown by a significant overall effect of diet $[F(1,83)=6.18, p<.002]$ and a higher percentage of open-arm entries for diazepamtreated animals, as shown by a significant effect of drug treatment $[F(2,83)=18.50, p<.001]$. Post hoc analysis indicated that the treatment with diazepam significantly increased this measure in control animals for both doses used $(p<.05)$, but did it only after the higher dose in malnourished animals (Figure 1). This lower reactivity of malnourished animals to diazepam led to a statistically significant effect of diet $\times$ drug treatment interaction $[F(2,83)=3.10, p<.05]$. Regarding the percentage of time spent in the open arms, an ANOVA indicated that malnourished animals spent significantly more time in the open arms, as shown by an overall effect of diet $[F(1,83)=$ $8.82, p<.01]$, and that diazepam-treated animals increased the time spent in the open arms, as shown by a significant effect of drug treatment $[F(2,83)=12.81, p<.001]$. Post hoc analysis indicated that diazepam significantly increased the time spent in open arms in control animals for both doses used $(p<.05)$, but did it only after the higher dose in malnourished animals (Figure 1). This lower reactivity of malnourished animals to diazepam led to a statistically significant effect of diet $\times$ drug treatment interaction $[F(2,83)=3.72, p<.05]$. An ANOVA for the number of closed-arm entries indicated a significant effect of drug treatment $[F(2,83)=11.09, p<.001]$. Post hoc analysis indicated that diazepam reduced the number of closed-arm entries in malnourished animals for both doses used $(p<.05)$, but did it only after the higher dose in control animals (Figure 1).

An ANOVA indicated a higher latency of the first arm entry for malnourished animals than for control animals, as shown by a significant effect of $\operatorname{diet}[F(1,83)=5.30$, $p<.02$ ] (Figure 2). Treatment with diazepam decreased the attempts to enter open arms, as indicated by a significant effect of drug treatment $[F(2,83)=9.16, p<.001]$. 

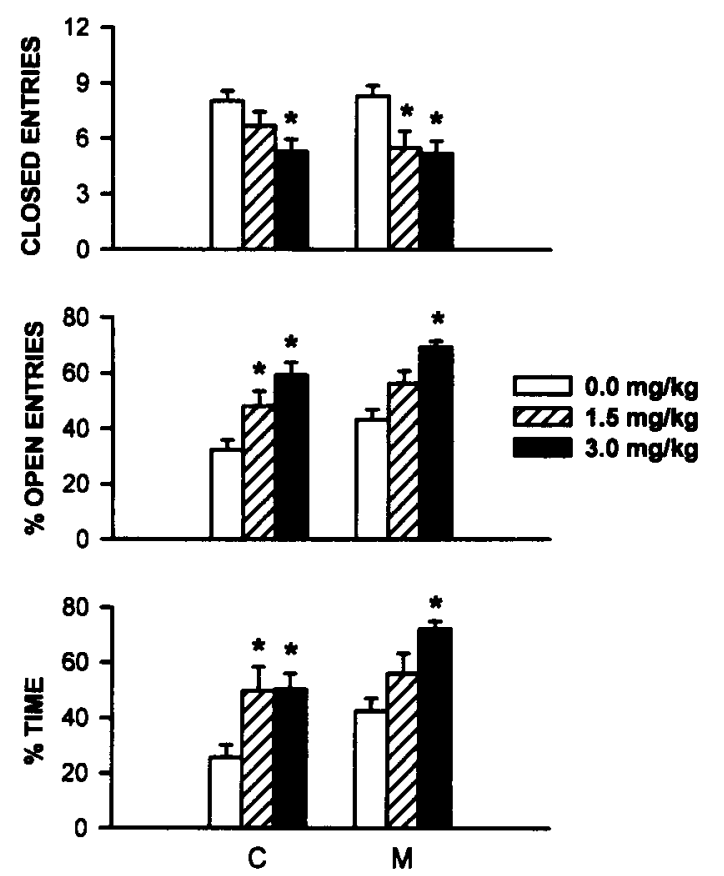

Figure 1. Mean $\pm S E M(n=10-12)$ number of closed-arm entries, percentages of open-arm entries, and percentages of time spent in the open arms for control (C) and malnourished (M) rats treated with vehicle or diazepam ( 1.5 and $3 \mathrm{mg} / \mathrm{kg}$ ), $30 \mathrm{~min}$ before the test in the elevated plus-maze. ${ }^{*} p<.05$, relative to vehicletreated animals (Dunnett's test).

Post hoc analysis indicated that this overall effect was mainly due to a decrease in the frequency of attempts to enter open arms in control animals after $1.5 \mathrm{mg} / \mathrm{kg}$ of diazepam $(p<.05)$. Neither $3.0 \mathrm{mg} / \mathrm{kg}$ for controls or both doses for malnourished animals significantly changed the attempts to enter open arms (Figure 2). Diazepam also decreased the number of rearings, as indicated by a significant effect of drug treatment $[F(2,83)=13.66, p<$ $.001]$. Post hoc analysis indicated that diazepam treatment decreased the frequency of rearing in both doses for control and malnourished animals $(p<.05)$.

An ANOVA indicated a higher number of closed-arm returns in control animals, as shown by a significant effect of diet $[F(1,83)=5.20, p<.02]$. There was a trend toward a decrease in the number of closed-arm returns after diazepam, as shown by a borderline significant effect of drug treatment $[F(2,83)=2.89, p=.06]$ (Figure 3 ). The number of head-dips, on the other hand, was significantly increased by drug treatment $[F(2,83)=$ $4.52, p<.01]$, and a trend toward a significantly higher frequency of head-dips in malnourished animals was found $[F(1,83)=3.43, p=.06]$ (Figure 3). Post hoc analysis showed that only malnourished animals treated with $3.0 \mathrm{mg} / \mathrm{kg}$ of diazepam significantly increased the number of head-dips, relative to vehicle-treated animals $(p<.05)$. Diazepam significantly decreased the number of stretch-attend postures, as evidenced by a significant effect of drug treatment $[F(2,83)=3.86, p<.02]$ (Fig- ure 3). Post hoc analysis showed that this overall effect of drug treatment was mainly due to a decrease in the number of stretch-attend postures in control animals treated with $1.5 \mathrm{mg} / \mathrm{kg}$ of diazepam $(p<.05)$, since no other comparisons were statistically significant.

Time in the central platform and grooming were not affected by diet or pharmacological treatment.

\section{DISCUSSION}

The results of the present study show that the proteincalorie malnutrition significantly reduced the body weight of the animals, as previously described in the literature (Bedi, 1994; Boxwell, Ayson, \& Ramenofsky, 1995; Finger \& Green; 1983; Peeling \& Smart, 1994). In addition, it was found that this kind of malnutrition technique produced a decrease in body weight similar to that previously described in our lab using the protein-restriction technique (Almeida et al., 1990, 1991; Almeida et al., 1992; Lima, de Oliveira, Lachat, Dal-Bo, \& Almeida, 1993).

Interestingly, the behavior of malnourished animals in the elevated plus-maze test also agrees with previous data derived from studies using only protein restriction. In both cases, malnourished animals showed an increased exploration of the open arms of the elevated plus-maze, represented by a higher number of entries and a greater amount of time spent in the open arms. This pattern of behavior suggests a lower anxiety of animals submitted to these two malnutrition methods. Additionally, a longer
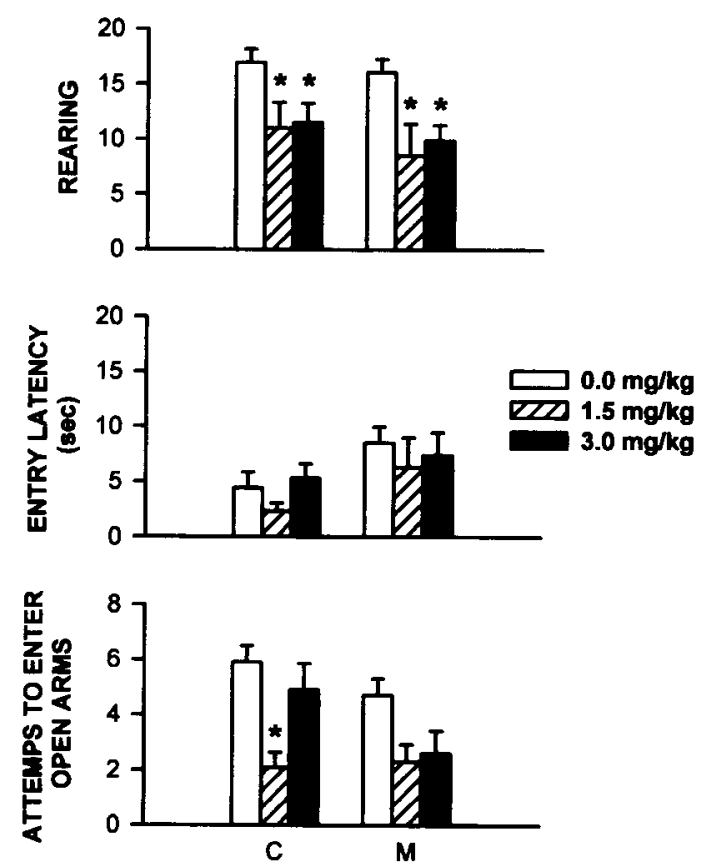

Figure 2. Mean $\pm S E M(n=10-12)$ number of rearings, latencies for the first arm entry (entry latencies), and number of attempts to enter open arms for control (C) and malnourished (M) rats treated with vehicle or diazepam $(1.5$ and $3 \mathrm{mg} / \mathrm{kg}), 30 \mathrm{~min}$ before the test in the elevated plus-maze. ${ }^{*} p<.05$, relative to vehicle-treated animals (Dunnett's test). 

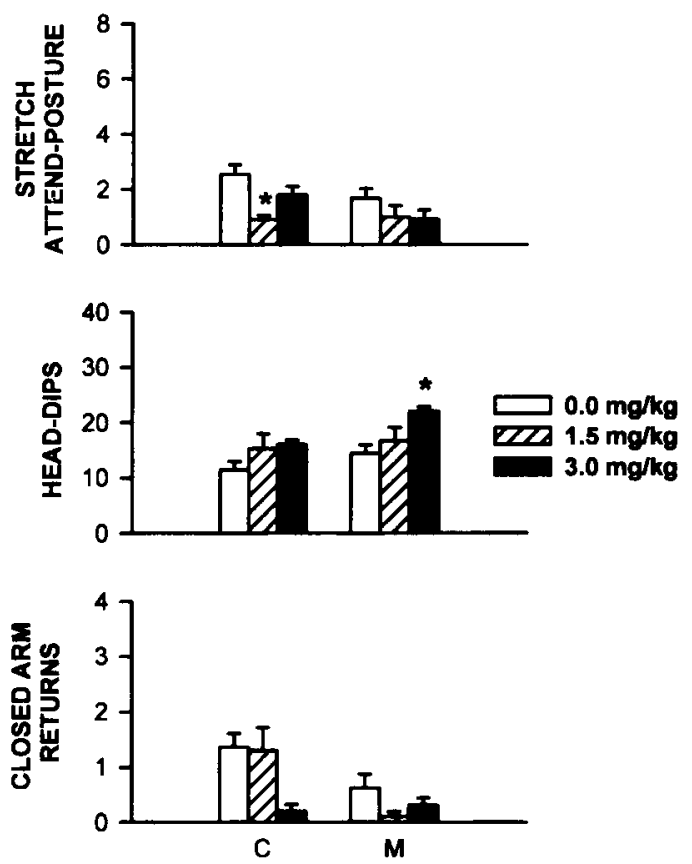

Figure 3. Mean $\pm S E M(n=10-12)$ numbers of stretch-attend postures, head-dips, and closed-arm returns for control $(C)$ and malnourished $(M)$ rats treated with vehicle or diazepam (1.5 and $3 \mathrm{mg} / \mathrm{kg}$ ), $30 \mathrm{~min}$ before the test in the elevated plus-maze. ${ }^{*} p<.05$, relative to vehicle-treated animals (Dunnett's test).

latency for the first arm entry, a lower number of closedarm returns, and a trend toward a higher number of headdips also support the interpretation of lower anxiety in protein-calorie-malnourished animals used in the present study. Since the closed-arm returns have been interpreted as a risk-assessment behavior (Almeida et al., 1994; Rodgers \& Cole, 1993a), this would suggest that proteincalorie-malnourished animals spend less time assessing the risks of a novel situation. This could explain, at least partially, the higher percentage of open-arm exploration in these animals. The higher percentage of open-arm entries in malnourished animals, relative to control animals, cannot be explained in terms of changes in locomotor activity, since the absolute number of closed-arm entries (a good indicator of general motor activity in the maze; Cruz et al., 1994; File, 1992) was not modified by diet treatment (Figure 1). Although this higher open-arm exploration can suggest lower anxiety of protein-caloriemalnourished animals, another explanation based on impulsiveness could be attempted. Pre- and postnatal malnutrition changes performance in a procedure of differential reinforcement of low rates, suggesting increased impulsiveness (Brioni \& Orsingher, 1988; Tonkiss, Galler, Formica, Shukitt-Hale, \& Timm, 1990). Thus, the present results could also be interpreted as higher impulsiveness - that is, protein-calorie malnutrition could lead to deficits in behavioral inhibition during the plusmaze test, resulting in increased exploration of the open arms. This hypothesis is particularly interesting because early malnutrition causes alterations in the structure
(Cintra, Díaz-Cintra, Galvan, Kemper, \& Morgane, 1990; Jordan, Howells, McNaugthon, \& Heatlie, 1982; Lewis, Patel, \& Balaz, 1979), neurophysiology (Austin, Bronzino, \& Morgane, 1986; Austin-LaFrance, Morgane, \& Bronzino, 1991; Bronzino, Austin-LaFrance, \& Morgane, 1990, 1991a, 1991b; Jordan \& Clark, 1983), and neurochemistry (Blatt, Chen, Rosene, Volicer, \& Galler, 1994; Chen, Tonkiss, Galler, \& Volicer, 1992) of the hippocampal formation, a brain region especially important in the modulation of behavioral inhibition in mammals (Gray, 1982a, 1982b).

In addition, the results of the present study also show that protein-calorie-malnourished animals are hyporeactive to the anxiolytic effects of diazepam in the elevated plus-maze test, relative to control animals. This hyporeactivity was evidenced in the percentage of open-arm entries, time spent in the open arms, attempts to enter open arms, and stretch-attend postures. On the other hand, the similarities between control and malnourished animals in the response to diazepam in the number of rearings (indicative of exploration) and in the number of closed-arm entries (indicative of locomotor activity) suggest that the hyporeactivity of malnourished animals in this test is restricted to behavioral categories believed to represent anxiety. However, the reactivity of malnourished animals to diazepam in head-dipping behavior cannot be easily understood. One possible explanation, in the case of head-dipping behavior, is that malnourished animals explore more the open arms of the maze. Thus, since the malnourished animals spent more time in this section of the maze, it contributed to a better opportunity to display this behavior, particularly after the treatment with the higher dose of diazepam. However, despite the difficulties in explaining results of this behavioral category, it is clear that malnourished animals are hyporeactive to the anxiolytic effects of diazepam when we consider other behavioral categories expressing anxiety (percentage of open arms entry, time spent in the open arms, closed-arm returns, and head-dips). This hyporeactivity agrees with previous results reported in protein-malnourished rats submitted to several animal models of anxiety in our lab (Almeida et al., 1988; Almeida et al., 1990, 1991; Almeida et al., 1992; Santucci et al., 1994) and other labs (Brioni et al., 1989; Brioni \& Orsingher, 1988).

Similarities between the two malnutrition techniques in the behavioral expression of vehicle-treated animals suggest that protein-calorie malnutrition could be changing neural structures underlying anxiety behaviors in the same way that protein malnutrition affects these structures and causing the same behavioral changes in the plus-maze. Additionally, the similarities in the response to pharmacological treatment suggest that the GABAbenzodiazepine receptor system could be similarly affected by protein and protein-calorie malnutrition. In the case of protein malnutrition, it has been systematically reported that there are changes in the levels of glutamic acid decarboxylase and GABA and in the number of benzodiazepine receptors in several brain areas (Agarwal, Prassad, \& Taneja, 1981; Blatt, Rosene, Johnson, \& 
Galler, 1993; Rajalakshmi, Parameswaran, \& Ramakrishnan, 1974; Rajalakshmi, Parameswaran, Telang, \& Ramakrishnan, 1974; Telang, Fuller, Wiggins, \& Enna, 1984; Wiggins, Fuller, \& Enna, 1984), supporting the interpretation that these alterations are underlying changes in the reactivity of malnourished animals to the benzodiazepine anxiolytics (Almeida et al., 1988; Almeida et al., 1990, 1991; Almeida et al., 1996a; Santucci et al., 1994). Unfortunately, there are few and inconclusive data in the literature on the effects of the protein-calorie malnutrition upon neurochemical and structural parameters of the central GABA-benzodiazepine neurotransmitter system (Rathbun \& Druse, 1985). Despite the scarcity of data, it appears suggestive that similar changes are being produced by both protein and protein-calorie malnutrition in the GABA-benzodiazepine neurotransmitter system.

Finally, the data of the present study agree with previous reported data demonstrating that an ethopharmacological analysis of the elevated plus-maze test may contribute to the increase in the number of parameters that respond to benzodiazepine anxiolytics (Almeida et al., 1994; Almeida et al., 1993; Almeida et al., 1996c; Cole \& Rodgers, 1994; Cruz et al., 1994; Rodgers \& Cole, 1993a, 1993b). Especially important were the data of attempts to enter open arms, closed-arm returns, head-dips, and stretch-attend postures, showing that these behaviors are sensitive to treatment with diazepam. Considering that these last three categories are classified as riskassessment behaviors, then the results of the present study show that diazepam produces a reduction in the time the animals spend assessing the potential risks associated with the exploration of the elevated plus-maze. The consistent reduction of the amount of rearings produced by diazepam indicates that this drug changes not only behaviors specifically related to anxiety but also exploratory behavior. About $85 \%$ of rearing behavior is displayed in the closed arms. Therefore, the reduction in the number of rearings following treatment with diazepam could be the result of a significant increase in the time spent by the rats in the open arms, with an equivalent decrease in the time spent in the closed arms. Thus, in addition to classical measures, a series of novel rat behavioral categories can be now recorded in the elevated plus-maze, enriching future behavioral and pharmacological studies.

\section{REFERENCES}

Agarwal, K. N., Prassad, C., \& Taneja, V. (1981). Protein deprivation and the brain: Effect on enzymes and free amino acids related to glutamate metabolism in rats. Annals of Nutritional Metabolism, 25, 228-233.

Almeida, S. S., de Oliveira, L. M., Bichuette, M. Z., \& GraefF, F. G. (1988). Early malnutrition alters the effect of chlordiazepoxide on inhibitory avoidance. Brazilian Journal of Medical \& Biological Research, 21, 1033-1036.

Almeida, S. S., DE Oliveira, L. M., \& GraefF, F. G. (1990). Decreased reactivity to anxiolytics caused by early protein malnutrition in rats. Pharmacology, Biochemistry \& Behavior, 36, 997-1000.

Almeida, S. S., de Oliveira, L. M., \& Graeff, F. G. (1991). Early protein malnutrition changes exploration of the elevated plus-maze and reactivity to anxiolytics. Psychopharmacology, 103, 513-518.
Almeida, S. S., Garcia, R. A., Cibien, M. M. R., de Araujo, M., MorEIRA, G. M. S., \& DE OliveIra, L. M. (1994). The ontogeny of exploratory behaviors in early-protein-malnourished rats exposed to the elevated plus-maze test. Psychobiology, 22, 283-288.

Almeida, S. S., Garcia, R. A., \& de Oliveira, L. M. (1993). Effects of early protein malnutrition and repeated testing upon locomotor and exploratory behaviors in the elevated plus-maze. Physiology \& Behavior, 54, 749-752.

Almeida, S. S., Soares, E. G., Bichuette, M. Z., Graeff, F. G., \& DE OLjveira, L. M. (1992). Effects of early postnatal malnutrition and chlordiazepoxide on experimental aversive situations. Physiology \& Behavior, 51, 1195-1199.

Almeida, S. S., Tonkiss, J., \& Galler, J. R. (1996a). Malnutrition and reactivity to drugs acting in the central nervous system. Neuroscience \& Biobehavioral Reviews, 20, 389-402.

Almeida, S. S., Tonkiss, J., \& Galler, J. R. (1996b). Prenatal protein malnutrition affects avoidance but not escape behavior in the elevated T-maze test. Physiology \& Behavior, 60, 191-195.

Almeida, S. S., Tonkiss, J., \& Galler, J. R. (1996c). Prenatal protein malnutrition affects exploratory behavior of female rats in the elevated plus-maze test. Physiology \& Behavior, 60, 675-680.

Austin, K. B., Bronzino, J. D., \& Morgane, P. J. (1986). Prenatal protein malnutrition affects synaptic potentiation in the dentate gyrus of rats in adulthood. Developmental Brain Research, 29, 267-273.

austin-LaFrance, R. J., Morgane, P. J., \& Bronzino, J. D. (1991). Prenatal protein malnutrition and hippocampal function: Rapid kindling. Brain Research Bulletin, 27, 815-818.

BEDI, K. S. (1994). Undernutrition of rats during early life does not affect the total number of cortical neurons. Journal of Comparative Neurology, 342, 596-602.

Blatt, G. J., Chen, J., Rosene, D. L., Volicer, L., \& Galler, J. R. (1994). Prenatal protein malnutrition effects on the serotonergic system in the hippocampal formation: An immunocytochemical, ligand binding, and neurochemical study. Brain Research Bulletin, 34, 507 518.

Blatt, G. J., Rosene, D. L., Johnson, E., \& Galler, J. R. (1993). Prenatal protein malnutrition effects on the chemical neuroanatomy of the rat hippocampal formation. Anatomical Record Supplement, 1, 38.

Boxwell, J., Ayson, P., \& Ramenofsky, M. (1995). Growth and metabolic parameters in pups of undernourished lactating rats. Physiology \& Behavior, 57, 469-475.

Brioni, J. D., Córdoba, N., \& OrSingher, O. A. (1989). Decreased reactivity to the anticonflict effect of diazepam in perinatally undernourished rats. Behavioural Brain Research, 34, 159-162.

BRIONI, J. D., \& ORSINGHER, O. A. (1988). Operant behavior and reactivity to the anticonflict effect of diazepam in perinatally undernourished rats. Physiology \& Behavior, 44, 193-198.

Bronzino, J. D., Austin-LaFrance, R. J., \& Morgane, P. J. (1990). Effects of prenatal protein malnutrition on perforant path kindling in the rat. Brain Research, 515, 45-50.

Bronzino, J. D., Austin-LaFrance, R. J., \& Morgane, P. J. (1991 a). Effects of prenatal protein malnutrition on kindling-induced alteration in dentate granule cell excitability: I. Synaptic transmission measures. Experimental Neurology, 112, 206-215.

Bronzino, J. D., Austin-LaFrance, R. J., \& Morgane, P. J. (1991 b). Effects of prenatal protein malnutrition on kindling-induced alteration in dentate cell excitability: II. Paired-pulse measures. Experimental Neurology, 112, 216-223.

Chen, J., Tonkiss, J., Galler, J. R., \& Volicer, L. (1992). Prenatal protein malnutrition in rats enhances serotonin release from hippocampus. Journal of Nutrition, 122, 2138-2143.

Cintra, L., Díaz-Cintra, S., Galvan, A., Kemper, T., \& Morgane, P. J. ( 1990$)$. Effects of protein undernutrition on the dentate gyrus in rats of three age groups. Brain Research, 532, 271-277.

COLE, J. C., \& RodGers, R. J. (1994). Ethological evaluation of the effects of acute and chronic buspirone treatment in the murine elevated plus-maze test: Comparison with haloperidol. Psychopharmacology, 114, 288-296.

Cruz, A. P. M., Frei, F., \& GraefF, F. G. (1994). Ethopharmacological analysis of rat behavior on the elevated plus-maze. Pharmacology: Biochemistry \& Behavior, 49, 171-176.

de Onís, M., Monteiro, C., Akré, J., \& Clugston, G. (1993). The 
worldwide magnitude of protein-energy malnutrition: An overview from the WHO global database on child growth. Bulletin of the World Health Organization, 71, 703-712.

DOBBING, J. (1987). Early nutrition and later achievement. London: Academic Press.

FILE, S. E. ( 1992). Behavioural detection of anxiolytic action. In J. M. Elliott, D. J. Heal, \& C. A. Marsden (Eds.), Experimental approaches to anxiety and depression (pp. 25-44). Chichester, U.K.: Wiley.

Finger, S., \& GREEN, L. (1983). Early undernutrition and later hippocampal damage: I. DRL performance in rats. Nutrition \& Behavior, 1, 195-206.

GraY, J. A. (1982a). Multiple book review of the neuropsychology of anxiety: An enquiry into the functions of the septo-hippocampal system. Behavioral \& Brain Sciences, 5, 469-534.

Gray, J. A. (1982b). The neuropsychology of anxiety: An enquiry into the functions of the septo-hippocampal system. Oxford: Oxford University Press.

JORDAN, R. C., \& ClARK, G. A. (1983). Early undernutrition impairs hippocampal long-term potentiation in adult rats. Behavioral Neuroscience, 97, 319-322.

Jordan, R. C., Howells, K. F., Mcnaugthon, N., \& Heatlie, P. L. (1982). Effects of undernutrition on hippocampal development and function. Research in Experimental Medicine, 180, 201-207.

LEvitSky, D. A., \& STRUPP, B. (1995). Malnutrition and the brain: Changing concepts, changing concerns. Journal of Nutrition, 125 , $2212 \mathrm{~S}-2220 \mathrm{~S}$

LEWIS, P. D., PATEl, A. J., \& Balaz, R. (1979). Effect of undernutrition on cell generation in the rat hippocampus. Brain Research, 168, 186-189

lima, J. G., de Oliveira, L. M., Lachat, J. J., Dal-Bo, C. M. R., \& Almeida, S.S. (1993). Comparison of the effects of lab chow and casein diets based on body and brain development of rats. Brazilian Journal of Medical \& Biological Research, 26, $1069-1076$.

LISTER, R. G. (1987). The use of a plus-maze to measure anxiety in the mouse. Psychopharmacology, 92, 180-185.

Morgane, P. J., Austin-LaFrance, R. [J.], Bronzino, J. D., Tonkiss, J., Díaz-Cintra, S., Cintra, L., Kemper, T., \& Galler, J. R. (1993). Prenatal malnutrition and development of the brain. Neuroscience \& Biobehavioral Reviews, 17, 91-128.

Morgane, P. J., Austin-LaFrance, R. J., Bronzino, J. D., Tonkiss, J., \& GALLER, J. R. (1992). Malnutrition and the developing nervous system. In R. L. Isaacson \& K. F. Jensen (Eds.), The vulnerable brain and environmental risks: Vol. I. Malnutrition and hazard assessment (pp. 3-44). New York: Plenum.

Morgane, P. J., Miller, M., Kemper, T., Stern, W., Forbes, W., Hall, R., Bronzino, J. D., Kissane, J., Hawrylewicz, E., \& Res-
NICK, O. (1978). The effects of protein malnutrition on the developing central nervous system in the rat. Neuroscience \& Biobehavioral Reviews, 2, 137-230.

Peeling, A. N., \& Smart, J. L. (1994). Successful prediction of immediate effects of undernutrition throughout the brain growth spurt on capillary and synapse-to-neuron ratio of cerebral cortex in rats. Metabolic Brain Disease, 9, 81-95.

Pellow, S., Chopin, P., File, S., \& Briley, M. (1985). Validation of open:closed arm entries in an elevated plus-maze as a measure of anxiety in the rat. Journal of Neuroscience Methods, 14, 149-167.

Rajalakshmi, R., Parameswaran, M., \& Ramakrishnan, C. V. (1974). Effects of different levels of dietary protein on brain glutamate dehydrogenase and decarboxilase in young albino rats. Journal of Neurochemistry, 23, 123-127.

Rajalakshmi, R., Parameswaran, M., Telang, S., \& RamakrishNAN, C. V. (1974). Effects of undernutrition and protein deficiency on glutamate dehydrogenase and decarboxylase in rat brain. Journal of Neurochemistry, 23, 129-133.

Rathbun, W. E., \& DRUSE, M. (1985). Maternal undernutrition during lactation: Effect on amino acids in brain regions of offspring. Journal of Neurochemistry, 45, 1802-1808.

Rodgers, R. J., \& Cole, J. C. (1993a). Anxiety enhancement in the murine elevated plus-maze by immediate prior exposure to social stress. Physiology \& Behavior, 53, 383-388.

Rodgers, R. J., \& Cole, J. C. (1993b). Influence of social isolation, gender, strain, and prior novelty on plus-maze behaviour in mice. Physiology \& Behavior, 54, 729-736.

Santucci, L. B., Daud, M. M., Almeida, S. S., \& de Oliveira, L. M. (1994). Effects of early protein malnutrition and environmental stimulation upon the reactivity to diazepam in two animal models of anxiety. Pharmacology, Biochemistry \& Behavior, 49, 393-398.

STRUPP, B. J., \& LEVITSKY, D. A. (1995). Enduring cognitive effects of early malnutrition: A theoretical reappraisal. Journal of Nutrition, $125,2221 \mathrm{~S}-2232 \mathrm{~S}$.

Telang, S., Fuller, G., Wiggins, R., \& EnNa, S. J. (1984). Early undernutrition and gama-aminobutyric acid binding in rat brain. Journal of Neurochemistry, 43, 640-645.

Tonkiss, J., Galler, J. R., Formica, R. N., Shukitt-Hale, B., \& TIMm, R. R. (1990). Fetal protein malnutrition impairs acquisition of a DRL task in adult rats. Physiology \& Behavior, 48, 73-77.

WigGins, R., Fuller, G., \& ENNA, S. (1984). Undernutrition and the development of brain neurotransmitter systems. Life Science, $\mathbf{3 5}$, 2085-2094.

(Manuscript received July 18, 1996; revision accepted for publication December 3, 1996.) 